\title{
Heterotrimeric G protein-dependent WNT-5A signaling to ERK $1 / 2$ mediates distinct aspects of microglia proinflammatory transformation
}

Carina Halleskog ${ }^{1}$, Jacomijn Petronella Dijksterhuis ${ }^{1}$, Michaela Brita Christina Kilander ${ }^{1}$, Javier Becerril-Ortega ${ }^{1}$, Juan Carlos Villaescusa², Eva Lindgren ${ }^{1}$, Ernest Arenas $^{2}$ and Gunnar Schulte ${ }^{1^{*}}$

\begin{abstract}
Background: WNT-5A signaling in the central nervous system is important for morphogenesis, neurogenesis and establishment of functional connectivity; the source of WNT-5A and its importance for cellular communication in the adult brain, however, are mainly unknown. We have previously investigated the inflammatory effects of WNT/ $\beta$-catenin signaling in microglia in Alzheimer's disease. WNT-5A, however, generally recruits $\beta$-catenin-independent signaling. Thus, we aim here to characterize the role of WNT-5A and downstream signaling pathways for the inflammatory transformation of the brain's macrophages, the microglia.

Methods: Mouse brain sections were used for immunohistochemistry. Primary isolated microglia and astrocytes were employed to characterize the WNT-induced inflammatory transformation and underlying intracellular signaling pathways by immunoblotting, quantitative mRNA analysis, proliferation and invasion assays. Further, measurements of $\mathrm{G}$ protein activation by $\left[\mathrm{\gamma}^{-35} \mathrm{~S}\right] \mathrm{GTP}$ binding, examination of calcium fluxes and cyclic AMP production were used to define intracellular signaling pathways.

Results: Astrocytes in the adult mouse brain express high levels of WNT-5A, which could serve as a novel astroglia-microglia communication pathway. The WNT-5A-induced proinflammatory microglia response is characterized by increased expression of inducible nitric oxide synthase, cyclooxygenase-2, cytokines, chemokines, enhanced invasive capacity and proliferation. Mapping of intracellular transduction pathways reveals that WNT-5A activates heterotrimeric $G_{i / o}$ proteins to reduce cyclic AMP levels and to activate a $G_{i / o}$ protein/phospholipase C/calcium-dependent protein kinase/extracellular signal-regulated kinase 1/2 (ERK1/2) axis. We show further that WNT-5A-induced ERK1/2 signaling is responsible for distinct aspects of the proinflammatory transformation, such as matrix metalloprotease 9/13 expression, invasion and proliferation.

Conclusions: Thus, WNT-5A-induced and G protein-dependent signaling to ERK1/2 is important for the regulation of proinflammatory responses in mouse primary microglia cells. We show for the first time that WNT-5A/G protein signaling mediates physiologically important processes in primary mammalian cells with natural receptor and G protein stochiometry. Consequently, WNT-5A emerges as an important means of astrocyte-microglia communication and we, therefore, suggest WNT-5A as a new player in neuroinflammatory conditions, such as neurodegenerative disease, hypoxia, stroke, injury and infection.
\end{abstract}

Keywords: Frizzled, Heterotrimeric G proteins, MAPK, Non-canonical WNT signaling, Cyclic AMP, Microglia, Neuroinflammation

\footnotetext{
* Correspondence: gunnar.schulte@ki.se

'Dept. Physiology \& Pharmacology, Sec. Receptor Biology \& Signaling,

Karolinska Institutet, Nanna Svartz väg 2, Stockholm S-17177, Sweden

Full list of author information is available at the end of the article
} 


\section{Background}

WNT-5A belongs to the WNT family of secreted lipoglycoproteins which is composed of 19 WNTs in mammals and is crucial for stem cell proliferation and differentiation during embryonic development [1-3]. During central nervous system (CNS) development, WNTs regulate stem cell proliferation and differentiation, functional integration, axonal growth, neuronal connectivity and activity [4,5]. Recent evidence also indicates that WNTs in the adult CNS regulate stem cells and maintain tissue homeostasis, and they have also been implicated in neurological disorders $[5,6]$.

WNTs interact with and activate several different cell surface receptors of which the Class Frizzled (FZD) belongs to the group of $\mathrm{G}$ protein-coupled receptors (GPCRs) [7]. WNT-5A, in contrast to, for example, WNT-1 and -3A, generally activates $\beta$-cateninindependent signaling $[3,8-10]$. In various cell systems it was shown that WNT-5A activates $\mathrm{WNT} / \mathrm{Ca}^{2+}$ signaling, the WNT/RAC1 and WNT/RHO pathway [11] involving the phosphoproteins disheveled 1, 2, 3 (DVL1, 2, 3), which are viewed as a signaling hub relaying many WNT signaling routes [12]. Further, heterotrimeric $G$ proteins have been implicated in WNT/FZD signal transduction [13-16] and, indeed, recent studies confirmed a previous supposition that WNTs can induce the activation of heterotrimeric G proteins [17-19]. Among classical downstream targets of GPCR signaling are the mitogen-activated protein kinases (MAPK) and especially the extracellular signal-regulated kinases ERK1/2 [20], which can be activated by many GPCRs irrespective of which $\mathrm{G}$ protein family the receptors associate with $[21,22]$.

Here, we examined the WNT-5A-induced communication to ERK1/2 and its relevance for the inflammatory transformation of mouse primary microglia, the immunocompetent cells of the CNS [23]. We show that WNT-5A is expressed in astrocytes and that it induces a rapid and transient phosphorylation of the ERK $1 / 2$ by recruitment of $\mathrm{G \alpha}_{\mathrm{i} / \mathrm{o}}$ heterotrimeric $\mathrm{G}$ proteins, phospholipase $C$ (PLC), calcium-dependent protein kinase (PKC) and the MAPK/ERK1/2 kinase (MEK1/2) in microglia. Further, recombinant and purified WNT-5A induces a proinflammatory transformation of mouse primary microglia as determined by increased expression of inflammatory markers, cytokines, chemokines and matrix metalloproteases, enhanced invasive capacities, and increased microglial proliferation. Employing the MEK1/2 inhibitor SL327 [24], we found that microglial proliferation, invasion and expression of matrix metalloproteases depend on the activation of heterotrimeric $G$ proteins and the subsequent phosphorylation of ERK1/2. Thereby, we identify a novel function of WNT-5A as a proinflammatory regulator of microglia and pinpoint a novel signal transduction pathway downstream of WNT-5A with the $\mathrm{Ga}_{\mathrm{i} / \mathrm{o}}$ protein- dependent activation of ERK1/2 underlying distinct aspects of the proinflammatory transformation of microglia.

\section{Methods}

Immunohistochemistry

Adult C57Bl6 mouse brains were collected and fixed in $4 \%$ paraformaldehyde (PFA) in PBS (4\% PFA) for $24 \mathrm{~h}$ at $4{ }^{\circ} \mathrm{C}$. Fixed brains were cryoprotected in $15 \%$ to $30 \% \mathrm{su}-$ crose in PBS, and sectioned using a Microm HM 560 cryostat. Mouse brains were sectioned at $16 \mu \mathrm{m}$ thickness and mounted on Superfrost Plus glass slides (Thermo Fisher Scientific Inc. Rockford, IL, USA). Sections were treated for antigen retrieval (\#S1699, DAKO Sweden AB, Stockholm, Sweden), washed with PT20 (PBS, 0.5\% Tween-20), blocked with PBTA (PBS, 0.1\% BSA, 0.3\% Triton X-100, 5\% Donkey serum) and incubated with primary antibodies diluted in PBTA, overnight at $4^{\circ} \mathrm{C}$. The primary antibodies in this study included the following: rat anti-WNT-5A (1:50, \#MAB645, R\&D Systems, Minneapolis, MN, USA), rabbit anti-IBA1 (1:500, \#019-19741, Wako, Neuss, Germany) and mouse anti-glial fibrillary acidic protein (GFAP) Cy3 conjugated (1:250, \#C9205, Sigma-Aldrich Sweden AB, Stockholm, Sweden). After washing with PT20, slides were incubated with secondary antibodies diluted in PBTA for one hour at room temperature (Alexa anti-rat 488 and Alexa anti-rabbit 647, Invitrogen, Stockholm, Sweden). Slides were washed and mounted with mounting medium (\#S3023, DAKO). Images were captured using a confocal microscope (LSM5 Exciter, Zeiss, Jena, Germany), and a maximum intensity projection of a Z-stack is presented $(5 \mu \mathrm{m})$.

\section{Primary cell cultures}

Microglia cells and astrocytes were prepared from newborn $\mathrm{C} 57 \mathrm{Bl} 6$ mice (postnatal day 1 to 3) according to the ethical permits N144/08 and N436/10; local ethical committee Stockholms Norra Djurförsöksetiska Nämnd. After decapitation, while the brains were kept in ice cold Hanks Balanced Salt Solution (HBSS; Invitrogen) blood vessels and meninges were removed with sterile forceps. Brains were rinsed four times with HBSS, and homogenized in (D)MEM, penicillin $(50 \mathrm{U} / \mathrm{mL})$, streptomycin $(50 \mu \mathrm{g} / \mathrm{mL})$, L-glutamine $(2 \mathrm{mM}), 10 \%$ fetal bovine serum (FBS) and Fungizon $(0.5 \mu \mathrm{g} / \mathrm{ml})$ (all from Invitrogen), with a $10 \mathrm{ml}$ pipette, then ten times with a $10 \mathrm{ml}$ syringe and needle (23 G) and then filtered through a cell strainer (70 $\mu \mathrm{m}$; BD Falcon, Stockholm, Sweden) into a $50 \mathrm{ml}$ falcon tube. After ten minutes centrifugation (900 g) the pellet was resuspended in fresh medium, filtered again and cultured in $75 \mathrm{~cm}^{2}$ flasks (one brain/flask). Medium was changed every fourth day, and after 10 to 12 days microglia cells were separated from the underlying astrocytic monolayer by gentle agitation. The composition of primary mixed astrocyte cultures used for Figure 1 was 

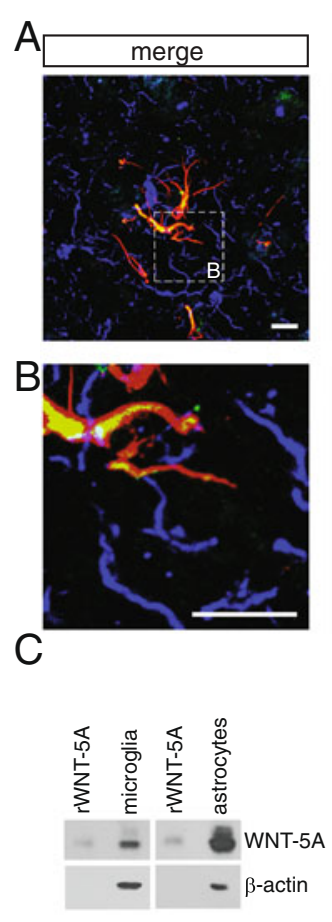
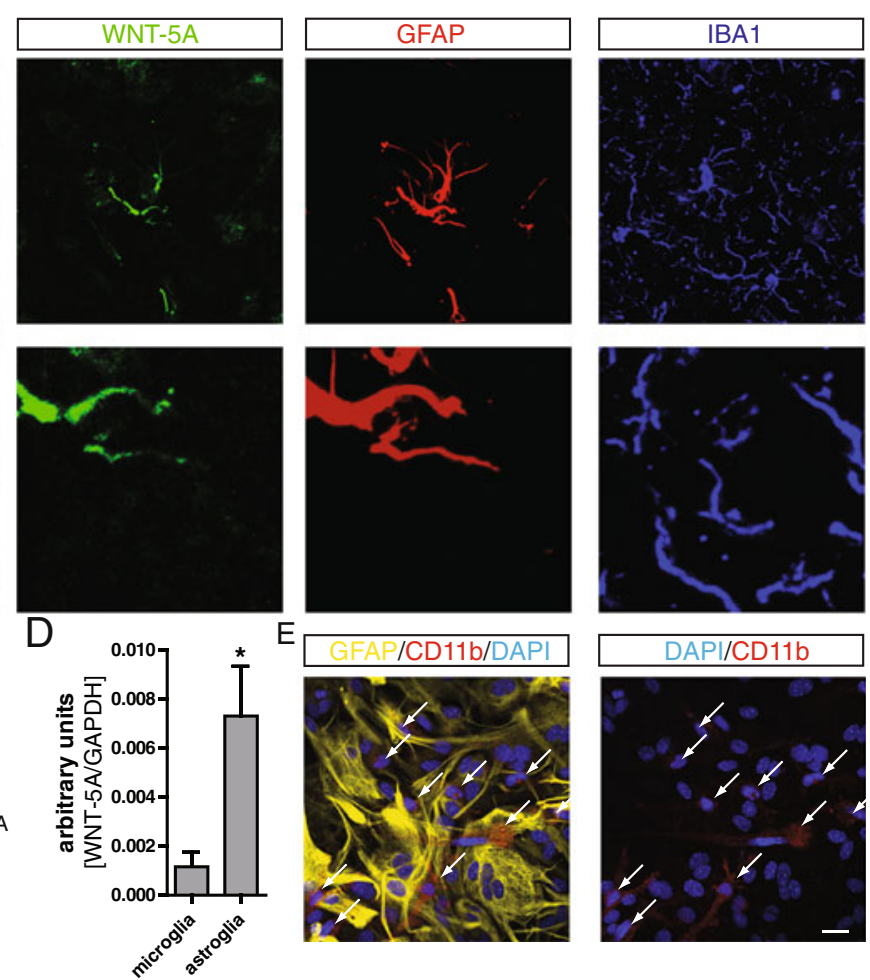
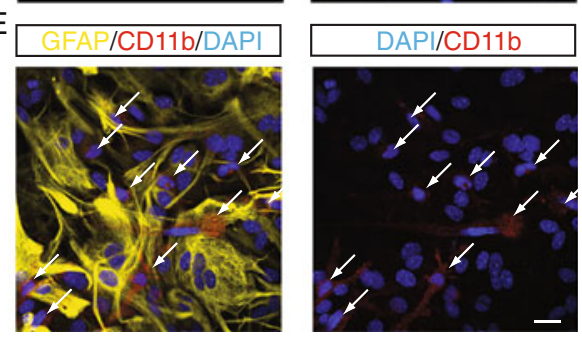

Figure 1 WNT-5A expression in mouse GFAP ${ }^{+}$astrocytes. (A) Immunohistochemistry was performed on adult mouse brain sections using an anti-WNT-5A antibody in combination with anti-glial fibrillary acidic protein (GFAP) and ionized calcium-binding adaptor protein 1 (IBA1) antibodies as astrocyte and microglia marker, respectively. Merge presents the overlay of IBA1, GFAP, WNT-5A. Size bar -2 $\mu$ m. The images represent a maximum intensity projection of a Z-stack of $5 \mu \mathrm{m}$ thickness. The white square marked 'B' indicates the area magnified in $\mathrm{B}$ : (B) Close up of a GFAP ${ }^{+}$astrocyte reveals the expression of WNT-5A in this cell type. (C) shows immunoblot detection of recombinant WNT-5A (rWNT-5A; $375 \mathrm{ng} / \mathrm{lane}$ ) in comparison to lysates from mouse primary microglia and mixed astrocyte cultures. $\beta$-actin serves as a loading control. (D) The bar graph depicts expression levels of WNT-5A mRNA in mouse primary microglia and mixed astrocyte cultures measured by QPCR. Data are normalized to GAPDH expression and analyzed with a non-parametric Mann-Whitney test. ${ }^{*}, P<0.05 ;{ }^{* *}, P<0.01 ;{ }^{* * *}, P<0.001$. $\mathrm{n}=4$ to 8. (E) shows indirect immunocytochemistry of mixed astrocyte cultures employing anti-GFAP as astrocyte and anti-CD11b as microglia markers. DAPI is used as nuclear counterstain. Image represents a maximum image projection of an $8 \mu \mathrm{m}$ Z-stack. Size bar $20 \mu \mathrm{m}$. The frame shows 63 cells in total and 10 CD11b-positive microglia (arrows). Routinely 10\% to 18\% microglia were observed ( $n=4)$. DAPI, 4',6-diamidino-2-phenylindole; GADPH, glyceraldehyde 3-phosphate dehydrogenase; n, number.

examined by immunocytochemistry using anti-GFAP (astrocyte marker) and anti-CD11b (microglia) revealing a low degree (10\% to $18 \%$ ) of contamination with CD11b-positive microglia (Figure 1E) comparable to what was reported earlier [25]. Microglia cells could be harvested three times from the same batch. The purity of the microglia cultures (>95\%) was validated by cytochemistry using fluorescein isothiocyanate (FITC)-conjugated Griffonia simplicifolia isolectin B4 (Sigma-Aldrich Sweden AB, Stockholm, Sweden) or anti-CD11b antibody in combination with anti-GFAP staining to assess contamination with astrocytes [see Additional file 1: Figure S4]. Cells were challenged 24 $\mathrm{h}$ after plating. For isolation of primary mixed astrocyte cultures, the remaining cells were trypsinated after microglia harvest and seeded according to experimental requirements.

\section{Immunoblotting}

Microglia cells were plated in a 24- or 48-well plate at a density of 150,000 or 100,000 cells/well, respectively. Twenty-four hours later, medium was changed to starvation medium (MEM, penicillin $(50 \mathrm{U} / \mathrm{mL})$, streptomycin (50 $\mathrm{\mu g} / \mathrm{mL}$; all from Invitrogen) overnight. Microglia cells were stimulated with recombinant carrier-free WNT-5A (CF WNT-5A; R\&D Systems) and inhibitors were added $30 \mathrm{~min}$ or $24 \mathrm{~h}$ (pertussis toxin (PTX) before stimulation. Stimulation was stopped by addition of lysis buffer (10\% glycerol, 1\% SDS, 100 mM Tris/HCl pH 7.4, bromophenol blue, $1 \%$ mercaptoethanol). Lysates of mixed astrocyte cultures were prepared after cells were cultured for 24 hours in 24 well plates $(500,000$ cells/ well). Lysates were homogenized with a hamilton syringe and samples were then separated through an $8 \%$ or $10 \%$ SDS PAGE and electrotransferred to Immobilon-P 
membranes (Millipore, Solna, Sweden). After blocking with $3 \%$ milk in TBS-T, the membranes were incubated with primary antibodies in blocking buffer: rabbit antiphosphospecific Thr202/Tyr204 ERK1/2 (1:1000; \#9101, Cell Signaling Technology, Boston, MA, USA), rabbit antiphosphospecific MEK1/2 (1:250; \#9121, Cell Signaling Technology), rabbit anti-P-LRP6 (1:1000; \#2568, Cell Signaling Technology), mouse anti- $\beta$-actin (1: 30.000; \#A5441, Sigma), mouse anti-DVL3 (1:500; \#sc-8027, Santa Cruz Biotechnology, Santa Cruz, CA, USA), mouse anti- $\beta$-catenin (1:1000; \#610154, BD Bioscience, Stockholm, Sweden), rat anti-WNT-5A (1:500; \#MAB645, R\&D Systems), rabbit anti-iNOS (1:1000; \#N7782, Sigma), goat anti-COX-2 (1:500; \#sc-13474, Santa Cruz) and goat antiTNFa (1:500; \#AF-410-NA, R\&D Systems) overnight at $4^{\circ} \mathrm{C}$. The proteins were immunodetected with appropriate horseradish peroxidase-conjugated secondary antibodies (goat anti-rabbit and goat anti-mouse (Pierce, Rockford, IL, USA) and rabbit anti-goat (Sigma) that were visualized by the enhanced chemiluminescence method (WesternLightning, PerkinElmer, Waltham, MA, USA).

\section{RNA isolation and PCR}

Microglia cells and mixed astrocytes cultures were seeded in six-well plates (Costar) at a density of 1.2 million/well. After 24 hours, cells were starved for four hours and then stimulated for six hours with CF WNT$5 \mathrm{~A} /$ control (ctrl). RNA was isolated using the RNeasy Mini kit (Qiagen, Hilden, Germany) and transcribed to cDNA using the high-capacity cDNA Archive kit (Applied Biosystems, Foster City, CA, USA). QPCR was performed in triplicate on an ABI Prism 7000 sequence detector and with the Taqman gene expression assay (Applied Biosystems) according to the manufacturer's instructions. Primer efficiency was previously tested by the manufacturer and shown to be close to $100 \%$ for all used primers. Additionally, primer efficiency was evaluated using the $\mathrm{C}_{\mathrm{T}}$ slope method over six serial cDNA dilutions indicating similar efficiencies close to $100 \%$ for all primers at the conditions used for analysis. All primer pairs were from Applied Biosystems: TNF- $\alpha$ : Mm00443260_g1, IL1ß: Mm00434228_m1, IL6: Mm9 9999064_m1, IL12: Mm01288991_g1, CCl12: Mm016 17100_m1, CCl7: Mm00443113_m1, MMP9: Mm004 429941_m1, MMP13: Mm00439491_m1, CD69: Mm0 1183378_m1, CD40: Mm00441891_m1, Cox-2 (Ptgs2): Mm00478374_m1, Fzd1: Mm01320682_s1, Fzd2: Mm025 24776_s1, Fzd3: Mm00445923_m1, Fzd4: Mm03053 556_s1, Fzd5: Mm00445623_s1, Fzd6: Mm00433383_m1, Fzd7: Mm01255614_s1, Fzd8: Mm00433419_s1, Fzd9: Mm01206511_s1, Fzd10: Mm00558396_s1. As an internal reference standard primers for GAPDH were used $\left(\Delta \mathrm{C}_{\mathrm{t}}=\mathrm{C}_{\mathrm{t}}\right.$, target gene $\left.-\mathrm{C}_{\mathrm{t}}, \mathrm{GAPDH}\right), \Delta \mathrm{C}_{\mathrm{t}}$ was presented as relative fold change in gene expression (mean \pm standard error of the mean (s.e.m)) indicated as arbitrary units, target gene/GAPDH. RT-PCR was performed with cDNA from unstimulated microglia in a 2720 Thermo Cycler (Applied Biosystems) using the following standard program: five minutes at $94^{\circ} \mathrm{C} ; 30$ cycles of 30 seconds at $94^{\circ} \mathrm{C}$; 45 seconds at $\mathrm{T}_{\text {anneal }}$; one minute at $72^{\circ} \mathrm{C}$; ten minutes at $72^{\circ} \mathrm{C}$. PCR products were run on $2.5 \%$ agarose gels and visualized using GelRed fluorescent nucleic acid gel stain (Biotium, Stockholm, Sweden). For primer sequences and $\mathrm{T}_{\text {anneal }}$ see [17].

\section{[ $\mathrm{\gamma}^{35}$ S]-GTP assay in microglia membranes}

Cells were seeded in $60 \mathrm{~mm}$ dishes (4 to 5 million cells/ dish). After 48 hours, cell plasma membrane proteins were isolated using the ProteoJet membrane protein extraction kit (Fermentas, Heidelberg, Germany) according to instructions provided by the manufacturer. $\left[\gamma^{35} \mathrm{~S}\right]$ GTP assay was performed as previously described [17]. In brief, the assay was performed in a 96-well filter plate (Millipore) in which $10 \mu \mathrm{g} /$ well of pre-activated (one hour, $37^{\circ} \mathrm{C}$ ) membrane protein were incubated (one hour, $30^{\circ} \mathrm{C}$ ) with $300 \mathrm{ng} / \mathrm{ml}$ WNT-5A or vehicle control $\left(0.01 \%\right.$ BSA in PBS) in the presence of $0.25 \mathrm{nM}\left[\gamma^{35} \mathrm{~S}\right]$ GTP (Perkin Elmer) and $5 \mu \mathrm{M}$ GDP (Sigma-Aldrich). All substances and protein were diluted in assay buffer (100 mM NaCl, 10 mM MgCl 2,20 mM HEPES, $\mathrm{pH}$ 7.4) to a final volume of $300 \mu \mathrm{l} /$ well. Subsequently, the plate was washed three times with $0.9 \%$ saline solution using vacuum filtration and dried overnight at $60^{\circ} \mathrm{C}$. Thirty microliters per well Optiphase supermix scintillation liquid (Perkin Elmer) were added and the incorporation of $\left[\gamma^{35}\right.$ S]-GTP was measured using a MicroBeta ${ }^{2}$ LumiJET Scintillation counter (Perkin Elmer).

\section{cAMP assay}

Intracellular cAMP levels were determined using a competitive protein binding assay and $\left[{ }^{3} \mathrm{H}\right]$-cAMP. Briefly, cells were plated into 24 well microplates, grown overnight and stimulated at $37{ }^{\circ} \mathrm{C}$. The reaction was stopped by addition of perchloric acid to a final concentration of $0.4 \mathrm{M}$ and incubation on ice. After lysis and neutralization with $\mathrm{KOH}$ in $50 \mathrm{mM}$ Tris, the supernatant was examined for cAMP content as described elsewhere [26].

\section{$\left[\mathrm{Ca}^{2+}\right]_{\mathrm{i}}$ imaging}

Primary microglia cells were harvested and placed in $35 \mathrm{~mm}$ dishes (100,000 cells per dish) coated with ECM Gel from Engelbreth-Holm-Swarm murine sarcoma (Sigma-Aldrich). Cells were loaded for 15 minutes at $37^{\circ} \mathrm{C}$ with $10 \mu \mathrm{M}$ Fluo-3/AM and $0.2 \%$ pluronic acid (F-127, Invitrogen) and incubated for an additional 15 minutes at $37^{\circ} \mathrm{C}$ in (D)MEM with HEPES $(12 \mathrm{mM})$ at $\mathrm{pH}$ 7.45. Experiments were performed at $37^{\circ} \mathrm{C}$ with continuous perfusion at $1 \mathrm{ml} /$ minute with a peristaltic 
pump, on the stage of a Zeiss inverted microscope and water immersion Zeiss C-Apochromat 40x/1.20 water correction M27 objective. Fluo-3 (excitation: $488 \mathrm{~nm}$, emission: $526 \mathrm{~nm}$; recorded range 503-629 nm) images were acquired every four seconds using Zen 2009 software (Zeiss). Measurements were performed on microglial cell bodies by using amplification rates that prevent saturation of the fluorescence signal and a preliminary calibration of the $\mathrm{Ca}^{2+}$ measurements.

\section{Mesoscale}

Primary microglia were stimulated with WNT-5A for 24 hours. The cell medium was cleared by centrifugation and analyzed for TNF $\alpha$ protein by a 96 well mouse cytokine immunoassay (Meso Scale Discovery, Gaithersburg, MD, USA) according to the manufacturer's instructions. TNF $\alpha$ concentrations in samples were compared with a dilution standard curve of recombinant TNF $\alpha$. Plates were analyzed with the SECTOR instrument and software.

\section{MTT-assay}

Cells were seeded in a 96-well plate $(40,000$ cells/well). The next day, medium was changed to starvation medium (total volume $100 \mu \mathrm{l} /$ well) for an additional 24 hours, after which cells were challenged with $300 \mathrm{ng} / \mathrm{ml} \mathrm{CF} \mathrm{WNT-5A}$ (R\&D Systems). After 24 hours of stimulation, $20 \mu \mathrm{l}$ of 3(4,5-dimethylthiazol-2-yl)-2,5-diphenyltetrazolium bromide (MTT) reagent solution (5 $\mathrm{mg} / \mathrm{ml}$ in PBS; Sigma) were added to each well, and also in a set of wells without cells to analyze background, and incubated for 3.5 hours at $37^{\circ} \mathrm{C}$ to allow for mitochondrial reduction of tetrazoles to formazan. After aspiration of the MTT solution, $150 \mu \mathrm{l} /$ well solvent ( $4 \mathrm{mM} \mathrm{HCl}$ and $0.1 \%$ Nonidet P-40 in isopropanol) were added and the plate was agitated for 20 minutes on an orbital shaker. Absorbance was read at $570 \mathrm{~nm}$ using a plate reader with a reference filter at $620 \mathrm{~nm}$. Increases in MTT were interpreted as increased proliferation since mitochondrial/metabolic activity correlates with cell number.

\section{Invasion assay}

A collagen mixture containing 10x (D)MEM, 5\% $\mathrm{NaHCO}_{3}$ (pH 8.97), HEPES $1 \mathrm{M}$ (pH 7.5) and rat collagen I (final concentration $3.6 \mathrm{mg} / \mathrm{ml}$, Gibco, Stockholm, Sweden) was placed on top of an extracellular matrix (ECM) gel (Sigma) coated 24-well glass bottom plate (MatTek Corporation, Ashland, MA, USA). After 90 minutes, the gel was fully polymerized and 50,000 fluorescently labeled primary microglia (cell tracker red $5 \mu \mathrm{M}$ for 30 minutes, Invitrogen) in $\alpha M E M$ growth medium containing either CF WNT-5A (300 ng/ml; R\&D systems) or PBS were placed on top of the layer. The next day, invasion of microglia into the collagen matrix was measured with a confocal microscope LSM710 system (Zeiss), scanning three random positions per condition and using Z-stack measurement with an EC Plan-Neofluar 10x/0.30 M27 objective, a $561 \mathrm{~nm}$ laser for excitation and an emission range of 566/683 $\mathrm{nm}$. During scanning, cells were kept in a humidified atmosphere at $37^{\circ} \mathrm{C}$ and $5 \% \mathrm{CO}_{2}$. Z-stacks were acquired with ZEN 2009 software. To quantify the percentage of invasion (cells that moved a minimum of $20 \mu \mathrm{m}$ from the top layer), the invading cells were divided by the total number of cells, employing the particle tracker function in Imaris 7.2 software (Bitplane). The results are shown for three independent experiments and invasion is normalized to the control.

\section{Statistical analysis}

Statistical and graphical analysis was performed using the Graph Pad Prism 5 software. All data, except quantitative PCR experiments were analyzed with one-way analysis of variance (ANOVA) followed by a Bonferroni's multiple comparison post hoc test. Quantitative PCR experiments were analyzed with a non-parametric MannWhitney test. All experiments were repeated at least three independent times. Levels of statistical significance: *, $P<0.05 ;$ **, $\mathrm{P}<0.01$; **;,$P<0.001$.

\section{Results}

\section{WNT-5A is expressed in astrocytes in vivo}

In order to address the role of WNT-5A for intercellular communication in the adult brain, we asked first of all, which cells express the WNT-5A protein. Immunohistochemistry in brain sections from adult mice with a rat-anti WNT-5A antibody in combination with an astrocyte (anti-GFAP) and a microglia marker (anti-IBA1) revealed strong overlap of WNT-5A- and GFAP-like immunoreactivity in the whole brain. Figure 1A, B show cortical WNT-5A- and GFAP-positive astrocytes and closely associated with IBA1-positive but WNT-5A-negative microglia. These data are supported by detection of WNT-5A protein and mRNA in primary microglia and mixed astrocyte cultures with immunoblotting (Figure 1C) and quantitative PCR (Figure 1D), respectively. The high expression levels of WNT-5A in mixed astrocyte cultures compared to microglia suggest a possible paracrine WNT-5A-based communication from astrocytes to microglia.

\section{WNT-5A stimulation of microglia results in phosphorylation of ERK1/2}

Activation of MAPKs is of central importance for the regulation of microglia activity in response to a plethora of stimuli ranging from lipopolysaccharides to cytokines, chemokines and neurotransmittors [27-29]. We hypothesized that WNT-5A, which is expressed in and secreted from astrocytes rather than by microglia themselves (Figure 1A, B) could regulate the inflammatory potential of microglia, possibly through 
MAPKs. These cells express suitable WNT-5A surface receptors as shown in Additional file 1: Figure S1 and in a previously published study [30]. In mouse primary microglia isolated from newborn mice, recombinant and purified WNT-5A increased the phosphorylation of ERK1/2 in a time- and dosedependent manner (Figure 2A, B). The WNT-5Aevoked ERK1/2 phosphorylation was rapid with increased levels at ten minutes post-stimulation and maximal induction $(138.2 \pm 6.2 \%$ of ctrl; mean \pm s.e.m. $)$ at 30 minutes. Two hours after WNT stimulation, PERK1/2 levels had returned to basal. Substantial efficacy of WNT-5A could be detected at $300 \mathrm{ng} / \mathrm{ml}$, a dose which has been previously shown to be effective to induce WNT-5A signaling in other cell types $[31,32]$. In order to confirm the specificity of the WNT-5A-induced P-ERK1/2 response we employed recombinant soluble FZD-related protein 1, which completely blocked the WNT-5A-induced ERK1/2 phosphorylation [see Additional file 1: Figure S2].

In parallel to the WNT-5A-induced ERK1/2 phosphorylation, we assessed phosphorylation of LRP6, $\beta$-catenin stabilization and the formation of phosphorylated and shifted DVL3 (PS-DVL3) [see Additional file 1: Figure S3]. According to previous findings in other cell types, WNT-5A did not activate the WNT/ $\beta$-catenin pathway, but increased the formation of PS-DVL in a time- and dose-dependent manner $[8,31]$.
WNT-5A activates heterotrimeric $\mathrm{Ga}_{\mathrm{i} / \mathrm{o}}$ proteins and induces $\left[\mathrm{Ca}^{2+}\right]_{i}$ in microglia

Since WNT-5A-induced signaling to ERK1/2 has not been described in detail yet, we aimed to characterize more closely the underlying signaling components. First of all, we used PTX as an inhibitor of $G \alpha_{\mathrm{i} / \mathrm{o}}$ proteins and show that pretreatment with PTX (100 ng/ml overnight) completely abrogated the WNT-5A-induced ERK1/2 phosphorylation (P-ERK1/2), indicating that activation of $\mathrm{G \alpha}_{\mathrm{i} / \mathrm{o}}$ is upstream of the WNT-5A-induced P-ERK1/2 (Figure 3A). On the other hand, PTX did not affect the WNT-5A-induced formation of PS-DVL (Figure 3B) similar to previous findings in SN4741 cells [31] arguing that $\mathrm{G}$ protein and DVL signaling could be distinct branches of WNT signaling. These biochemical data are supported by immunocytochemistry experiments showing that cellular P-ERK1/2 immunoreactivity was increased in microglia stimulated with WNT-5A, an effect which was also blocked by PTX pretreatment (Figure 3C).

In order to test the assumption that WNT-5A-induced ERK1/2 phosphorylation not only requires active $G \alpha_{i / o}$ protein but that WNT-5A also directly activates $G \alpha_{i / o}$, we performed $\mathrm{G}$ protein activation assays in membrane preparations from mouse primary microglia stimulated with recombinant WNT-5A (Figure 4A). Activation of heterotrimeric $\mathrm{G}$ proteins is measured as an exchange of GDP to GTP, employing a hydrolysis-resistant ${ }^{35}$ S-labelled GTP
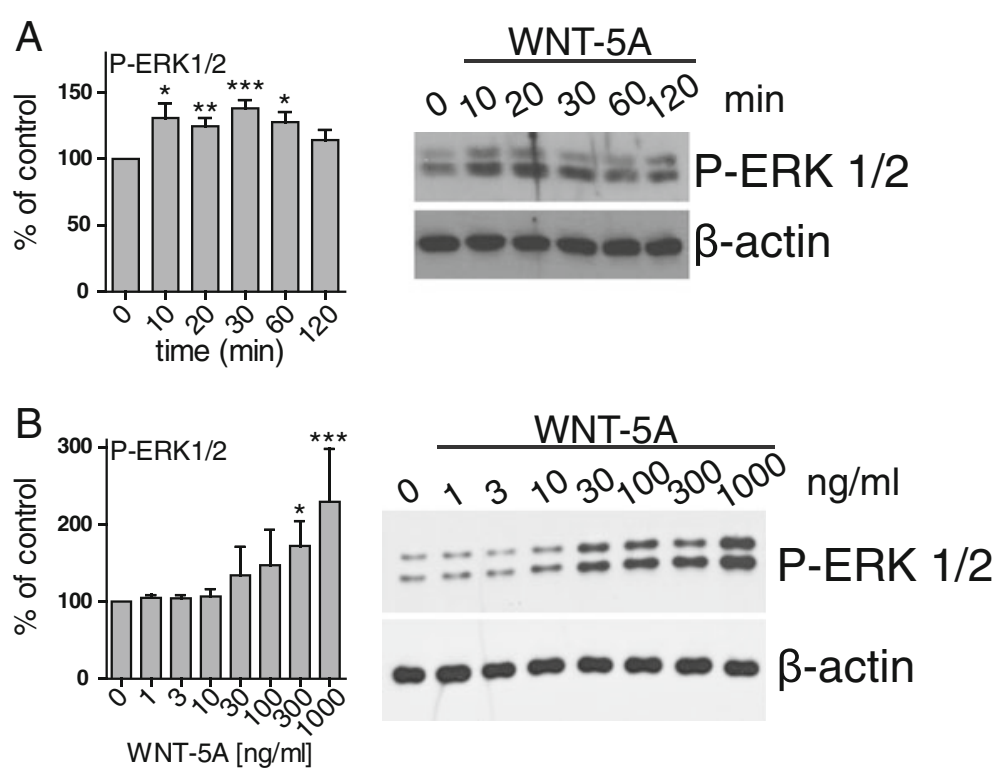

Figure 2 WNT-5A induced a transient phosphorylation of ERK1/2. WNT-5A stimulation of mouse primary microglia induced ERK1/2 phosphorylation in a time- $(\mathbf{A} ; 300 \mathrm{ng} / \mathrm{ml}$ WNT-5A) and dose-dependent (B; 30 minutes WNT-5A) manner. Bar graphs provide a summary of densitometric analysis of three independent experiments. Data were normalized to the response in ctrl-stimulated microglia. Variation is shown as s.e.m. $(\mathrm{n} \geq 3)$. ${ }^{*}, P<0.05 ;{ }^{* *}, P<0.01 ;{ }^{* *}, P<0.001$. ctrl, control; ERK1/2, extracellular signal-regulated kinase $1 / 2 ; n$, number; s.e.m, standard error of the mean. 

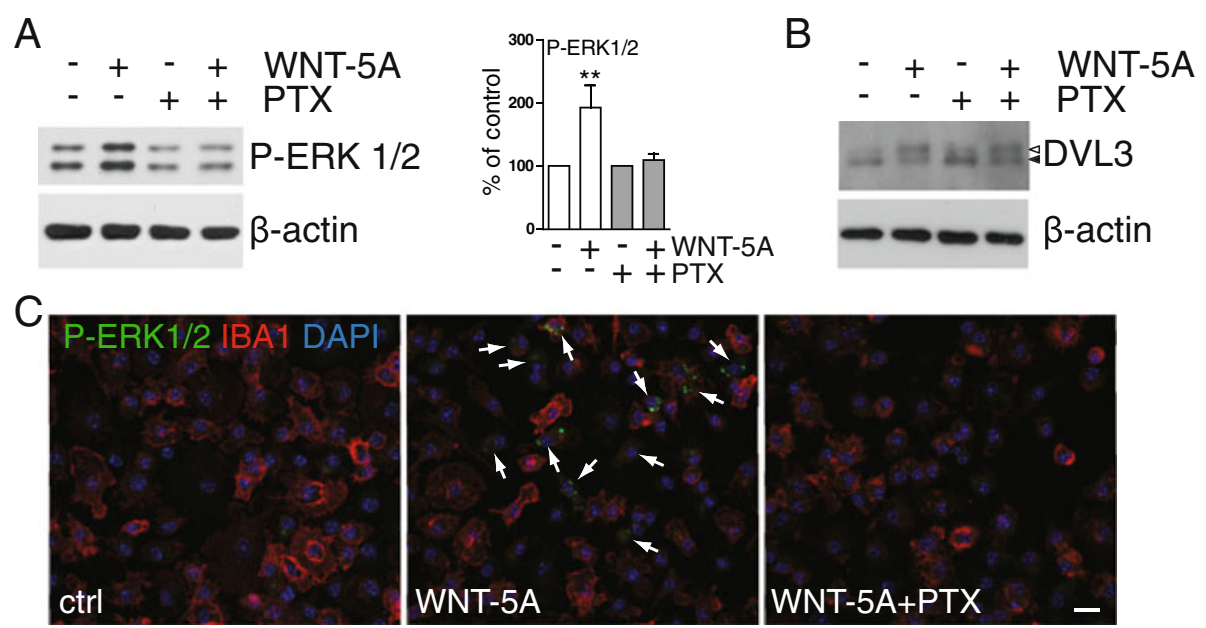

Figure 3 WNT-5A-induced ERK1/2 phosphorylation requires activation of $\mathbf{G a}_{\mathbf{i} / \mathbf{o}}$. (A) Primary microglia, pretreated with PTX (100 $\mathrm{ng} / \mathrm{ml}$, overnight), were stimulated with $300 \mathrm{ng} / \mathrm{ml}$ WNT-5A for 30 minutes and their total cell lysate was analyzed for P-ERK1/2 by immunoblotting. $\beta$ actin serves as a loading control. Densitometric analysis of three independent experiments is summarized in the bar graph (error bars - s.e.m.). ${ }^{* *}$, $P<0.01$. (B) In a similar stimulation paradigm, cells were lysed after two hours and the lysate was analyzed for the formation of PS-DVL3 (filled triangle: DVL3, open triangle: PS-DVL3). $n=3$. (C) Indirect immunocytochemistry and confocal microscopy were used to detect and localize PERK1/2 in ctrl, WNT-5A (300 ng/ml, 30 minutes) and WNT-5A/pertussis toxin (PTX, $100 \mathrm{ng} / \mathrm{ml}$ )-treated mouse primary microglia. IBA1 was used as a microglia marker and DAPI as nuclear counterstain. Arrows mark WNT-5A-responsive microglia with increased P-ERK1/2 levels $(n=3)$. Size bar $=50 \mu \mathrm{m}$. ctrl, control; DAPI, 4',6-diamidino-2-phenylindole; DVL, disheveled; ERK1/2, extracellular signal-regulated kinase 1/2; IBA1, ionized calcium-binding adaptor protein1; n, number; P-ERK1/2, ERK1/2 phosphorylation; PS-DVL, phosphorylated and shifted DVL; s.e.m., standard error of the mean.

analogue, $\left[\gamma_{-}{ }^{35} \mathrm{~S}\right] \mathrm{GTP}$. Crude $\left[\gamma_{-}{ }^{35} \mathrm{~S}\right] \mathrm{GTP}$ binding assays in mammalian cell membranes are generally suitable to assess GPCR-mediated activation of $\mathrm{G \alpha}_{\mathrm{i} / \mathrm{o}}$ proteins, due to the advantageous signal to noise ratio in comparison to $G \alpha_{s}$ or $G \alpha_{q / 11}$ proteins [33]. As shown in Figure 4A, WNT-5A stimulation resulted in GDP/GTP exchange, demonstrating that WNT-5A activates $\mathrm{G \alpha}_{\mathrm{i} / \mathrm{o}}$ proteins with $157.7 \pm 4.3 \%$ of control (mean \pm s.e.m.) at physiological stochiometry of receptors and $\mathrm{G}$ proteins. In order to characterize the expression profile of PTX-sensitive $G \alpha_{i / o}$ subunits in primary microglia, we performed RT-PCR (Figure 4B), which revealed expression of $\mathrm{G \alpha}_{\mathrm{i} 1}, \mathrm{i}_{\mathrm{i}}$, $\mathrm{i}_{3}$, o but not $\mathrm{G \alpha}_{\mathrm{t} 1}, 2,3$. Consequently, WNT-5A-induced stimulation in microglia can potentially activate $\mathrm{G \alpha}_{\mathrm{i1}-3}$ and $\mathrm{G \alpha}_{\mathrm{o}}$. $\mathrm{G \alpha}_{\mathrm{i} / \mathrm{o}}$-coupled GPCRs typically reduce cAMP levels through $G \alpha_{\mathrm{i} / \mathrm{o}}$ subunits and induce changes in intracellular calcium $\left(\left[\mathrm{Ca}^{2+}\right]_{\mathrm{i}}\right)$ through the release of $\beta \gamma$ and the subsequent phospholipase C (PLC)-dependent production of inositoltrisphosphate and calcium release from the endoplasmatic reticulum [22].

WNT-5A was indeed capable of reducing forskolininduced cAMP levels in a dose-dependent manner, functionally confirming the activation of $\mathrm{G \alpha}_{\mathrm{i} / \mathrm{o}}$ proteins (Figure 4C). In order to visualize WNT-5A-induced changes in $\left[\mathrm{Ca}^{2+}\right]_{i}$ we used Fluo-3-loaded primary microglia cells for live cell imaging. As shown in Figure 4D-F, $300 \mathrm{ng} / \mathrm{ml}$ WNT-5A led to a fast and transient increase in $\left[\mathrm{Ca}^{2+}\right]_{\mathrm{i}}$ in a PTX-sensitive manner reminiscent of previous observations in mammalian cells $[34,35]$.

\section{WNT-5A recruits a $\mathrm{Ga}_{\mathrm{i}}, \mathrm{PLC}, \mathrm{PKC}, \mathrm{MEK} 1 / 2$ signaling axis to regulate ERK $1 / 2$}

Classical $\mathrm{G \alpha}_{\mathrm{i} / \mathrm{o}}$-coupled GPCRs can recruit numerous pathways to activate ERK1/2 [22]. Based on our data on G protein activation and calcium mobilization, we hypothesized that WNT-5A could recruit PLC, $\mathrm{Ca}^{2+}$ and $\mathrm{Ca}^{2+}$-dependent PKC in order to feed into the classical MAPK cascade. To characterize the WNT-5Ainduced pathway to ERK1/2 in more detail, we employed a series of pharmacological inhibitors [see also Additional file 1: Table S1]: M119 (inhibits $\beta \gamma$-effector interaction); U73122 (inhibits PLC); bisindolmaleimide VIII (BIS; inhibits PKC); BAPTA-AM (a $\left[\mathrm{Ca}^{2+}\right]_{i}$ chelator); wortmannin and LY294002 (inhibit phosphatidylinositol-3'-kinase/ PI3K); SL327 (inhibits MEK1/2); and D4476 (casein kinase 1 inhibitor). Preincubation with M119, U73122, BIS, and SL327 but not wortmannin/LY294002 or D4476 completely blocked the WNT-5A-induced ERK1/2 response (Figure 5A), suggesting the involvement of $\beta \gamma$ release, PLC, PKC and MEK1/2 but not PI3K and CK1. The activity of D4476 was confirmed by analysis of PS-DVL3 levels: since the formation of PS-DVL3 is dependent on CK1 we could observe a reduced basal shift in DVL3 upon D4476 


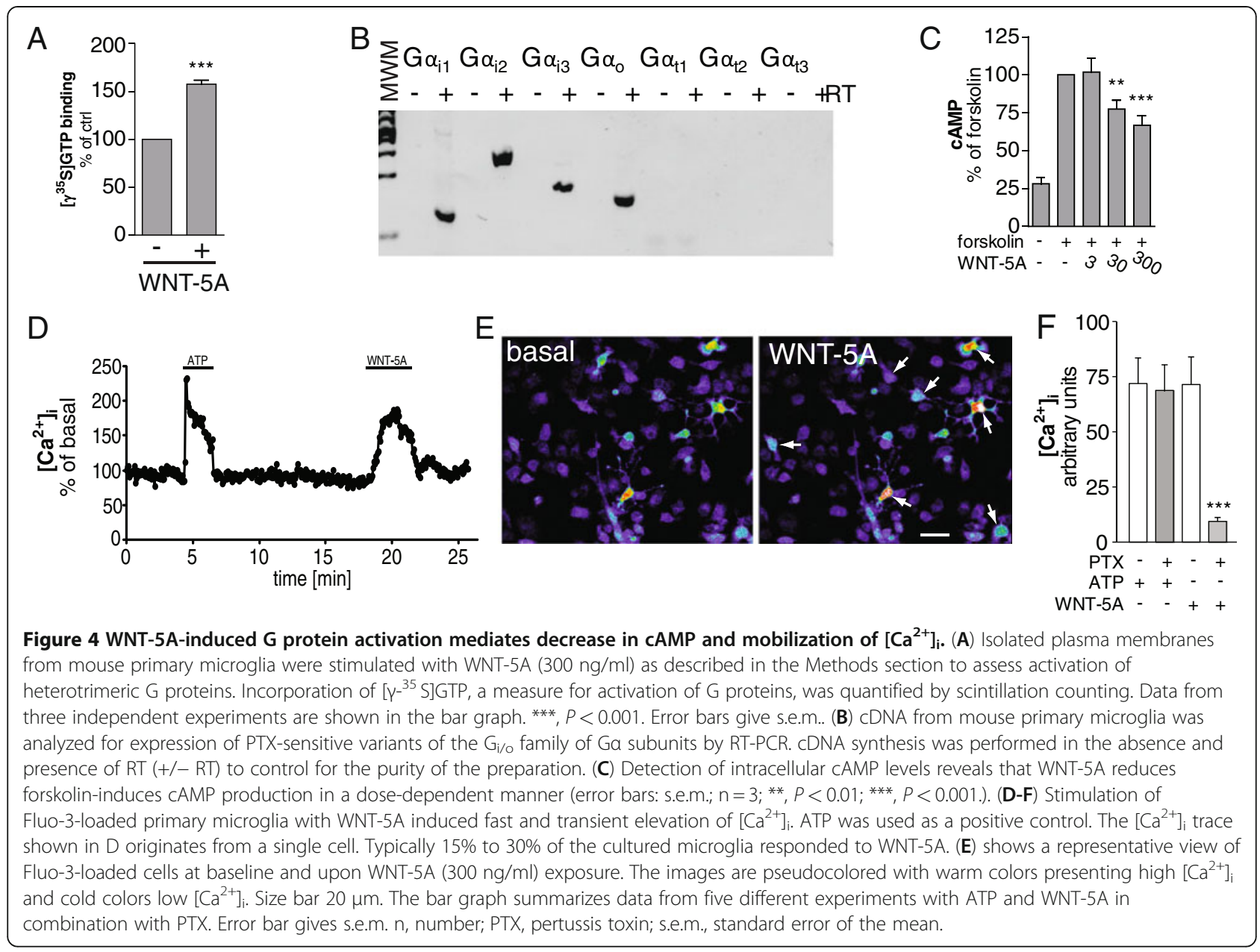

treatment (Figure 5B) comparable to previous data obtained in other cell types $[31,36]$.

Hence, our data indicate the involvement of $\beta \gamma$ subunits released from $G \alpha_{i / o}$, PLC, PKC, and MEK1/2 in the WNT-5A-induced signaling axis to ERK1/2 and its independence from CK1, PS-DVL3 formation and PI3K. The active involvement of MEK1/2 is corroborated by direct immunoblotting showing that MEK1/2 is phosphorylated upon WNT-5A treatment. In addition, we show that BIS and U73122 block WNT-5A-mediated MEK1/2 phosphorylation, confirming that it is regulated by the same upstream components (Figure 5A).

In summary, this suggests that WNT-5A can activate PS-DVL-dependent pathways, which we have not investigated in more detail in this study. In addition, WNT$5 \mathrm{~A}$ activates heterotrimeric $\mathrm{G}$ protein signaling, which leads to a reduction in CAMP levels and the activation of ERK1/2 through engagement of $\beta \gamma$ subunits, PLC, PKC, and MEK1/2. The ERK1/2 cascade is an established proliferative pathway with proinflammatory function in microglia [20,28,29,37]. Thus, based on the signaling profile induced by WNT-5A we suggest that its effects might be of a proliferative and proinflammatory nature in mouse primary microglia.

\section{Increased expression of iNOS, COX-2 and TNFa upon WNT-5A exposure}

To assess the proinflammatory potential of WNT-5A we initially employed immunoblotting to measure regulation of proinflammatory markers, which are generally induced upon activation of microglia: inducible nitric oxide synthase (iNOS), cyclooxygenase 2 (COX-2) and TNF $\alpha$. iNOS generates the reactive and cell permeable mediator nitric oxide, COX-2 is a crucial player in prostanoid synthesis and TNF $\alpha$ is an important proinflammatory cytokine. Six-hour stimulation with $300 \mathrm{ng} / \mathrm{ml}$ WNT-5A increased iNOS, COX-2 and TNF $\alpha$ expression substantially (Figure 6A, B). In order to support the TNF $\alpha$ protein expression data from cell lysates with information on WNT-5Ainduced mediator release, supernatants from ctrl- and WNT-5A-stimulated primary microglia were analyzed for TNF $\alpha$ by Mesoscale measurements, indicating an increased release of proinflammatory TNF $\alpha$ (Figure 6B'). 


\section{A}
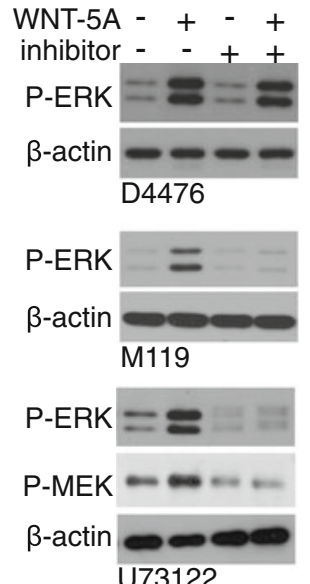
U73122
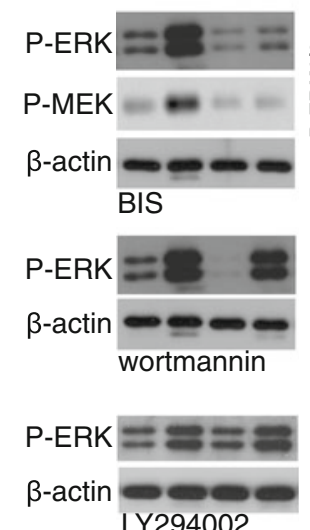

LY294002
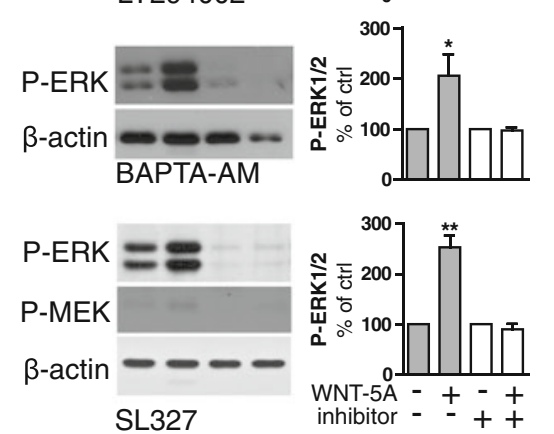

B SL327
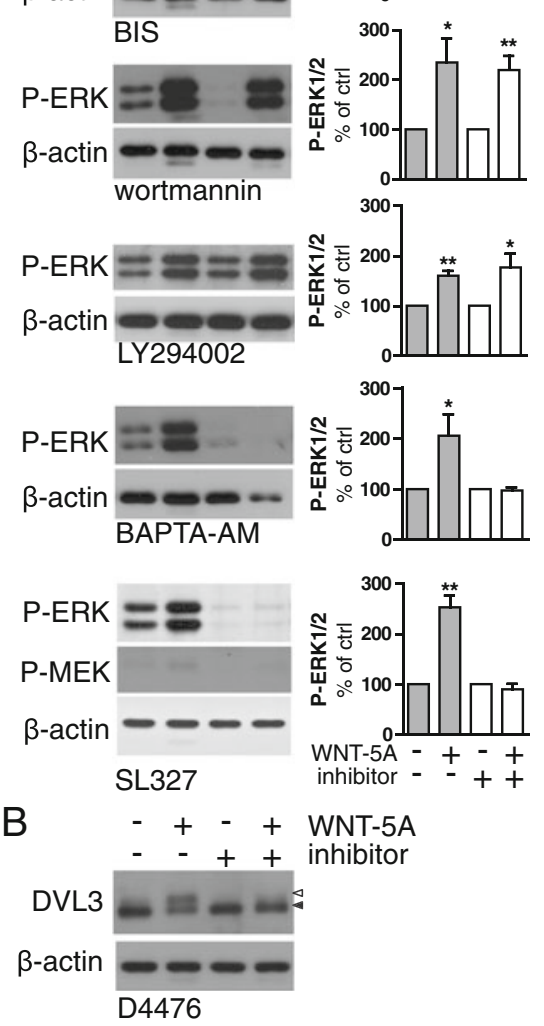

C

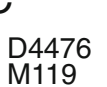

M119

U73122

BIS

\begin{tabular}{ccc} 
[inhib] & target & block \\
\hline $10 \mu \mathrm{M}$ & $\mathrm{CK} 1$ & $\mathrm{No}$
\end{tabular}

$10 \mu \mathrm{M} \quad \beta \gamma$

$10 \mu \mathrm{M}$ PLC

$10 \mu \mathrm{M}$ PKC

wortmannin $100 \mathrm{nM}$ PI3K

LY294002 $10 \mu \mathrm{M}$ PI3K

SL327
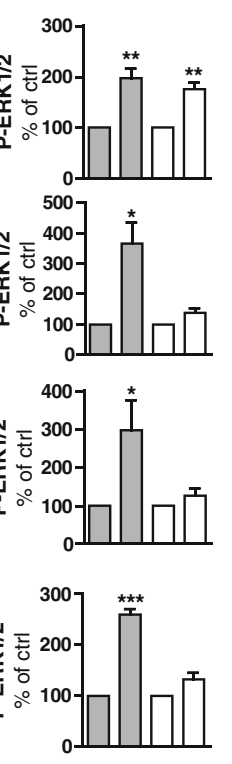

\section{政}




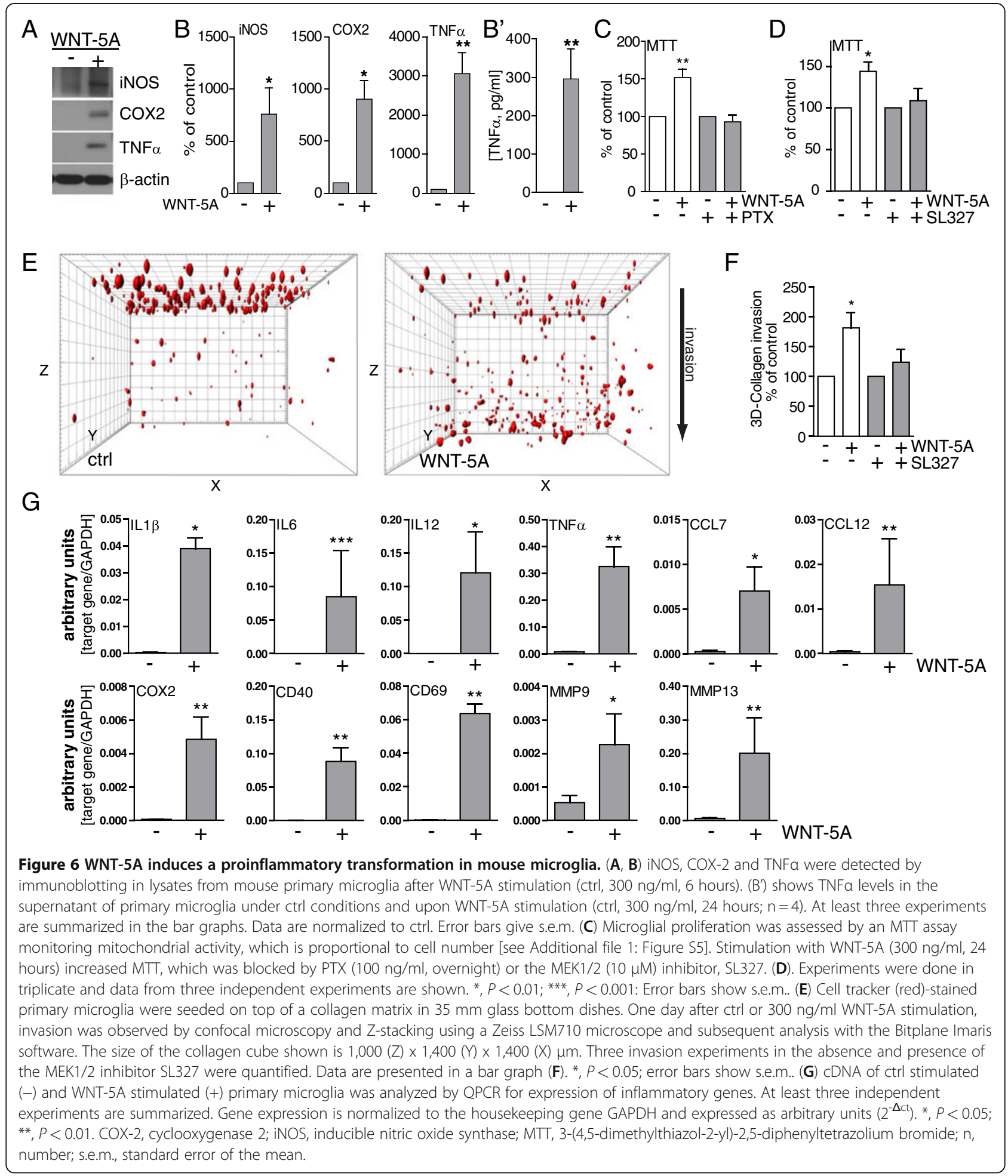

MMP13 after six hours of treatment with $300 \mathrm{ng} / \mathrm{ml}$ WNT-5A (Figure 6G). The observed shift in the expression profile of inflammatory genes with diverse functions clearly corroborates the proinflammatory action of WNT$5 \mathrm{~A}$ in microglia.
Since we have shown that WNT-5A-induced signaling to ERK1/2 is responsible for the recorded proliferative and invasive effects, we used the MEK1/2 inhibitor SL327 to assess the role of ERK1/2 signaling in the WNT-5A-induced regulation of gene expression. As 
shown in Table 1, WNT-5A-induced expression of genes for inflammatory markers was affected by SL327 in a bidirectional manner: whereas the increase of MMP9 and MMP13 expression was clearly blocked by MEK1/2 inhibition, the WNT-5A-induced effects on TNF $\alpha$, CCL7, CCL12, COX-2, and CD40 expression were instead amplified when MEK1/2 was inhibited.

The table summarizes QPCR data obtained from mouse primary microglia stimulated with $300 \mathrm{ng} / \mathrm{ml}$ WNT-5A for six hours in the presence and absence of the MEK1/2 inhibitor SL327 (10 $\mu \mathrm{M})$. Numbers provide the percentage of WNT-5A-induced increase over ctrl or SL327 treatment alone. Results are presented as arbitrary units (fold change of unstimulated control microglia, $\left.2^{-\Delta \Delta C t}\right)$. The ratio provides a relative measure of decrease (value $<1$ ) or increase $(>1)$ of gene expression upon treatment with SL327. Results from at least four independent experiments are shown. Variations are given as s.e.m. ${ }^{*}, P<0.05$; ${ }^{* *}, P<0.01$.

\section{Discussion}

WNT-5A, which is predominantly expressed in astrocytes in the adult mouse brain, evokes a proinflammatory transformation of microglia characterized by increased expression of cytokines, chemokines and metalloproteases and changes in microglial proliferation and invasiveness. We have characterized underlying signaling pathways, identifying a $\mathrm{Go}_{\mathrm{i} / \mathrm{o}}$-PLC-PKC-MEK-ERK1/2 signaling axis (see also Figure 7) as necessary for some but not all aspects of the WNT-5A-induced inflammatory transformation. Thus, we report for the first time that WNT-5A-induced signaling through heterotrimeric $G$ proteins and the ERK1/2 cascade is activated in cells with endogenous stoichiometry of WNT receptors and G proteins and that this has physiological relevance for the regulation of microglia in the brain and, thus, for the CNS immune response.

Table 1 Inhibition of MEK1/2 by SL327 blocks WNT-5Ainduced expression of matrix metalloproteases.

\begin{tabular}{llll}
\hline Gene & WNT-5A & WNT-5A/SL327 & Ratio \\
\hline IL1 $\beta$ & $209.8 \pm 78.2$ & $88.1 \pm 16.3$ & 0.4 \\
IL6 & $947.0 \pm 554.4$ & $541.0 \pm 175.8$ & 0.6 \\
IL12 & $33622.0 \pm 26855.0$ & $31504.0 \pm 14202.0$ & 0.9 \\
TNFa & $43.0 \pm 5.7$ & $366.3 \pm 84.5^{* *}$ & 8.5 \\
CCL7 & $29.1 \pm 5.1$ & $574.7 \pm 348.2^{*}$ & 19.7 \\
CCL12 & $26.7 \pm 7.0$ & $354.7 \pm 206.3^{* *}$ & 12.9 \\
COX-2 & $93.3 \pm 30.4$ & $448.3 \pm 169.9^{*}$ & 4.8 \\
CD40 & $558.0 \pm 133.0$ & $1989.0 \pm 398.0^{* *}$ & 3.6 \\
CD69 & $456.0 \pm 155.0$ & $1723.0 \pm 606.0$ & 3.8 \\
MMP9 & $5.1 \pm 1.2$ & $1.0 \pm 0.1^{*}$ & 0.2 \\
MMP13 & $28.3 \pm 8.0$ & $6.7 \pm 0.9^{* *}$ & 0.2 \\
\hline
\end{tabular}

\section{WNT-5A-evoked proinflammatory transformation of microglia}

The establishment and maintenance of regional and phenotypic differences in activated microglia are so far only poorly understood. The spectrum of WNT-5Ainduced changes suggests that microglia become activated, motile, proliferative, and communicate with their surroundings by means of secreted mediators. IL1 $\beta$, IL6, IL12 and TNF $\alpha$ act proinflammatory and are known to be secreted by activated microglia in many different conditions, such as neurodegenerative disease, trauma or infection [23,38]. These cytokines serve mainly for communication with surrounding microglia, macroglia and neurons but also infiltrating immune cells. In addition, we have investigated the expression of CC motif chemokines, namely CCL7 and CCL12, which are also known as monocyte chemotactic protein 3 and 5 , respectively. These chemokines are important for monocyte and leukocyte recruitment, indicating that WNT-5A-activated microglia could serve to engage peripheral, infiltrating immune cells to support neuroinflammatory processes $[39,40]$. Also, expression of CD40, a member of the tumor necrosis factor receptor family, and CD69, a C type lectin, serve for communication with astrocytes and peripheral immune cells, such as lymphocytes and natural killer cells [41]. Further, cytokines and chemokines are known to act both in a paracrine and autocrine manner, suggesting that their WNT-5A-induced release could also support communication among microglia to promote and spread the inflammatory response [42]. Additional transmission of inflammatory signals is accomplished by the WNT$5 \mathrm{~A}$-induced upregulation of iNOS and COX-2, which both have a crucial role in the inflammatory reaction and produce nitric oxide (NO) and prostaglandins, respectively [43].

\section{Regulation of MMPs by WNT-5A}

In addition to increasing NO-, prostaglandin-, cytokineand chemokine-based intercellular communication, WNT5A enhanced MMP9 and MMP13 expression, suggesting a role in extracellular matrix remodeling. The function of MMPs in the brain is complex and includes promotion of cell invasion as well as disruption of the blood-brain barrier [44-46]. Thus, increased invasion of microglia and recruitment of peripheral immune cells could be a consequence of MMP secretion from WNT-5A-stimulated microglia. Indeed, this assumption is supported by the WNT-5A-induced microglial invasion in the collagen three dimensional invasion assay (Figure 5E, F). Furthermore, MMPs contribute to the processing, activation and release of non-extracellular matrix proteins, such as growth factors, cytokines, FAS ligand, E-cadherin, integrins, and additional MMPs by a process called ectodomain shedding [47]. MMP13, 


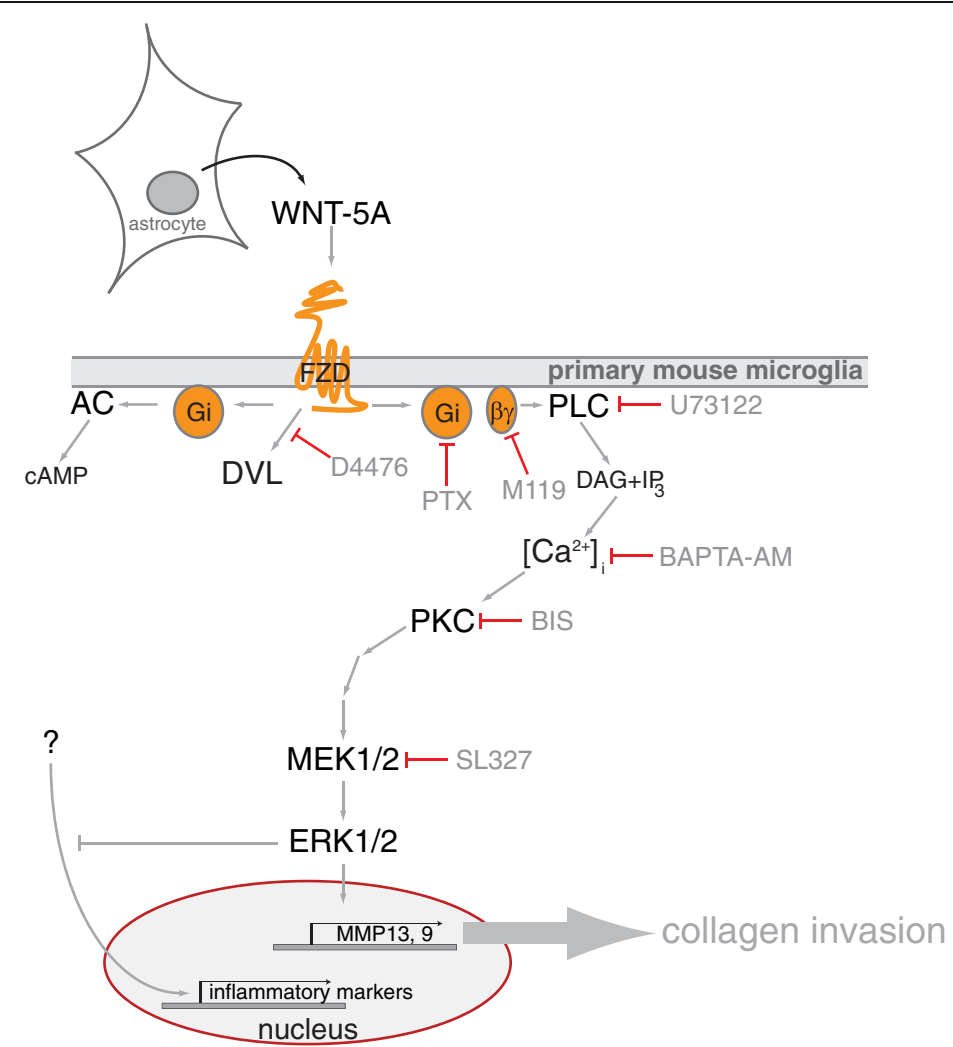

Figure 7 Schematic overview of the results from the present study indicating WNT-5A secretion from astrocytes and the WNT-5Ainduced signaling pathway towards ERK1/2 regulating distinct aspects of the proinflammatory transformation of microglia.

Pharmacological inhibitors used in the study: D4476, pertussis toxin (PTX), M119, BAPTA-AM, U73122, bisindolaleiimide (BIS), SL327. Abbreviations: AC, adenylyl cyclase; CAMP, cyclic AMP; DAG, diacylglycerol; DVL, disheveled; ERK1/2, extracellular signal-regulated kinases 1/2; FZD, Frizzled; IP3, inositoltriphosphate; MEK1/2, MAPK/ERK kinase 1/2; MMP, matrix metalloprotease; PLC, phospholipase C; PKC, $\mathrm{Ca}^{2+}$-dependent protein kinase; Gi, heterotrimeric $\mathrm{G}$ proteins of the $\mathrm{G}_{\mathrm{i} / \mathrm{o}}$ family; WNT, Wingless/int-1.

primarily a collagenase, is known to cleave many substrates [48], among others heparan sulfates. Since MMP13 was shown to promote the release of basic fibroblast growth factor [49] it similarly could release heparan sulfate-bound WNTs thereby amplifying WNT action in the inflammatory microenvironment.

\section{WNT-5A-induced ERK1/2 signaling in microglia}

In order to address the role of MEK $1 / 2$, the upstream kinase of ERK1/2, for the WNT-5A-induced changes in gene expression, we chose SL327 over more widely used PD98059 or UO126 because SL327 showed a higher solubility in ethanol over dimethyl sulfoxide (DMSO) among those substances. DMSO might interfere with the microglia integrity and activity status in long time stimulation paradigms, such as six or 24 hour, as used in the present study.

Most interestingly, WNT-5A-evoked MMP expression could be blocked by the MEK1/2 inhibitor SL327 (Table 1). On the other hand, WNT-5A-induced TNFa, CCL7, CCL12, COX-2 and CD40 expression was enhanced in the presence of MEK1/2 inhibition. These findings suggest a central regulatory role of the WNT5A-ERK $1 / 2$ pathway that is able to integrate proinflammatory input through a bidirectional regulation of gene expression. It appears that proinflammatory WNT-5A stimulation of primary microglia establishes a distinct reactive phenotype based on an integral inhibitory autoregulation through ERK1/2. ERK1/2 exerts an inhibitory input towards the ERK1/2-independent, WNT-5A-induced upregulation of TNFa, CCL7, CCL12, COX-2 and CD40, unmasked by simultaneous MEK1/2 inhibition (Table 1). Hypothetically, WNT-5A-induced ERK1/2 phosphorylation could also provide negative crosstalk with other proinflammatory agents, thereby limiting the inflammatory transformation or shifting it towards a more invasive and proliferative phenotype. So far we are not able to identify a candidate pathway, where the WNT-5A-ERK1/2 axis could exert negative regulation. The proposed crosstalk of WNT-5Ainduced ERK1/2 activation to attenuate other signaling systems could take place on different levels, such as the receptor level, intermediate signaling components, or the transcriptional levels. Further studies will be required to 
pinpoint candidate links and to map the underlying mechanisms of this regulatory crosstalk.

MAPK signaling in general and ERK1/2 in particular is a well-established pathway underlying CNS inflammation $[28,50]$. WNT-5A stimulation of primary microglia leads to a $\mathrm{G \alpha}_{\mathrm{i} / \mathrm{o}}, \mathrm{PLC}, \mathrm{Ca}^{2+}$, PKC, MEK1/2-dependent phosphorylation of ERK $1 / 2$, similar to pathways previously described for $\mathrm{G \alpha}_{\mathrm{i} / \mathrm{o}}$-coupled GPCRs [22]. Accordingly, $\mathrm{G \alpha}_{\mathrm{i} / \mathrm{o}}$-independent signaling could induce ERK1/2-independent aspects of microglial activation, for example, via formation of PS-DVL. ERK1/2 signaling downstream of GPCRs can almost be seen as a default pathway irrespective of the heterotrimeric $G$ proteins involved and agonistinduced activation of ERK1/2 is localized downstream of many different GPCRs [22].

However, WNT-induced signaling towards ERK1/2 cannot be observed as a general readout, which is confirmed by unpublished observations indicating that WNT-5A does not induce P-ERK1/2 upon 10 minutes of stimulation in human embryonic kidney cells (HEK293), mouse embryonic fibroblasts, a substantia nigra-derived dopaminergic precursor cell line SN4741 or N13 microglia-like cells (not shown).

\section{Astrocytes as source of proinflammatory WNT-5A}

Establishment of reactive microglia upon CNS damage precedes the development of astrogliosis, but both processes have overlapping inflammatory functions in CNS pathology [51]. Secreted factors from microglia are known to affect astrocytes and vice versa. During midbrain neurogenesis, astrocytes and radial glia were shown to increase the number of Nurr1 dopaminergic precursors through WNT-5A secretion [52], indicating that astroglia are an important source of CNS WNT-5A during development. Our findings now show that cultured astrocytes isolated from newborn mice and astrocytes in intact mouse brain tissue express WNT-5A suggesting a paracrine communication between astrocytes and surrounding cells such as microglia and neurons. Further, we show that mouse primary microglia in comparison to astrocytes express lower levels of WNT-5A mRNA and protein indicating that an autocrine regulation of microglia by WNT-5A could exist but that this might be of minor importance.

So far, the regulation of WNT-5A release from astrocytes to accomplish a proinflammatory transformation of surrounding microglia remains obscure. Since WNT$5 \mathrm{~A}$ protein levels in astrocytes are prominent also under normal conditions, we suggest that regulation of release mechanisms, possibly depending on transcriptional or functional regulation of Porcupine or WNTless [53] under proinflammatory conditions, could result in increased secretion of WNT-5A.

\section{Putative role of WNT-5A-induced proinflammatory transformation in pathophysiology}

Although the role of WNT-5A for brain development has been mapped in some detail, less is known of its involvement in brain disorders in the adult $[5,6,54,55]$. So far it is not known if levels of WNT-5A or its receptors are dynamically regulated under pathophysiological conditions, such as neurodegenerative disease, infection, trauma, hypoxia or other inflammatory conditions. One exception is brain tumors and metastases, which have been associated with overexpression of WNT-5A [56,57]. Brain tumors also increase the astrocyte- and microglia-dependent immune response and the presence of activated tumorassociated microglia was reported a long time ago [58]. In fact, recent data show that WNTs, and especially WNT$5 \mathrm{~A}$, signaling in microglia/macrophages, can promote invasiveness of breast cancer cells and especially their metastasis in the brain [59-61]. Most importantly, our study shows that microglia cells are WNT-receiving cells, which interpret WNT-5A stimulation with a strong proinflammatory output.

\section{Conclusions}

In summary, we identify WNT-5A originating from astrocytes as a proinflammatory regulator of microglia, capable of increasing their number and invasiveness, thereby supporting basic immune function in the CNS. Further, we show that distinct subsets of WNT-5Ainduced effects on microglial function are mediated through the ERK1/2 cascade. Thus, we conclude that WNT-5A has an important role to define a distinct proinflammatory phenotype of microglia in pathophysiological conditions associated with neuroinflammation. Future studies will reveal the putative crosstalk between G protein-dependent and -independent WNT-5A signaling in microglia and its role for the establishment and maintenance of a reactive microglia phenotype under different neuroinflammatory conditions.

\section{Additional file}

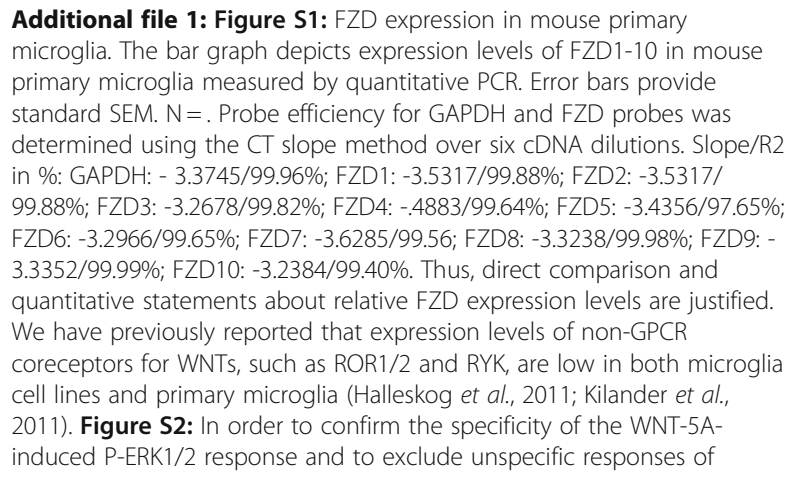


microglia to putative contaminants in the WNT preparation, we employed recombinant soluble FZD-related protein 1 (SFRP1). SFRP1 binds WNTs thereby preventing their interaction with the receptor (Kawano and Kypta, 2003; Kilander et al., 2011). Stimulation of primary microglia with WNT-5A $(300 \mathrm{ng} / \mathrm{ml})$ in the presence of SFRP1 $(10 \mu \mathrm{g} / \mathrm{\mu l})$ did not result in increased P-ERK1/2 arguing that SFRP1 sequesters WNT5 A selectively preventing its effects. $N=3$. Figure $\mathbf{S 3}$ : WNT-5A-induced $\beta$ catenin-independent WNT signaling. (A) Immunoblotting analysis of WNT-3A and WNT-5A stimulated cell lysates from mouse primary microglia cells reveals a WNT-5A-induced formation of PS-DVL3 but a lack of $\beta$-catenin stabilization and LRP6 phosphorylation. WNT-5A induced the dynamic formation of PS-DVL3 in a time- $(B)$ and dose-dependent (C) manner. $\beta$-actin was employed as a loading control. $N \geq 3$. Figure S4: Mouse primary microglia cultures seeded on gelatin-coated glass cover slips were routinely stained with indirect immunocytochemistry for the microglia marker CD11b and glial fibrillary acidic protein (GFAP). Counterstaining for nuclear DNA was done with DAPI. Cellular morphology is shown in the bright field image. Microglia culture contained $>95 \%$ CD11b+/GFAP-cells with microglial morphology. GFAP + astrocytes were only detected occasionally. Size bar: $50 \mu \mathrm{m}$. Figure S5: Mouse primary microglia cultures were stimulated with ctrl or $300 \mathrm{ng} / \mathrm{ml}$ WNT-5A for 24 hours. Cells were then manually counted in a Bürker chamber and data (normalized to control) summarized in a bar graph. WNT-5A increased cell number to $129.2 \pm 6.5$ (mean \pm s.e.m.). Variation is shown as s.e.m. $(n=4) .{ }^{*}, P<0.01$. Table S1:

Pharmacological inhibitors used in this study $[62,63]$.

\section{Abbreviations}

ANOVA: analysis of variance; BAPTA-AM: 1,2-bis(2-aminophenoxy)ethane-N,N, $\mathrm{N}, \mathrm{N}$-tetraacetic acid tetrakis (acetoxymethylester); BIS: bisindolmaleimide VIII; CCL: chemokine (CC-motif) ligand; CK: casein kinase; CNS: central nervous system; COX-2: cyclooxygenase 2; D4476: 4-(4-(2,3-dihydrobenzo[1,4]dioxin-6yl)-5-pyridin-2-yl-1 H-imidazol-2-yl)benzamide; (D)MEM: (Dulbecco's) modified Eagle's medium; DVL: disheveled; ERK1/2: extracellular signal-regulated kinase 1/2; ELISA: enzme-linked immunosorbent assay; FBS: fetal bovine serum; FZD: Frizzled; GFAP: glial fibrillary acidid protein; GPCR: G protein-coupled receptor; IBA1: ionized calcium-binding adaptor protein 1; LL: interleukin; iNOS: inducible nitric oxide synthase; LY294002: 2-(4-morpholinyl)-8-phenyl-1 (4 H)-benzopyran-4-one hydrochloride; MAPK: mitogen-activated protein kinase; MEK: MAPK/ERK1/2 kinase; MMP: matrix metalloprotease; MTT: 3-(4,5dimethylthiazol-2-yl)-2,5-diphenyltetrazolium bromide; PBS: phosphate buffered saline; PCR: polymerase chain reaction; PI3K: phosphatidylinositol-3'kinase; PKC: $\mathrm{Ca}^{2+}$-dependent protein kinase; PLC: phospholipase C; PSDVL: phosphorylated and shifted DVL; PTX: pertussis toxin; QPCR: quantitative reverse transcriptase PCR; s.e.m.: standard error of the mean; SFRP: secreted Frizzled-related protein; SL327: a-[amino-(4-aminophenylthio)methylene)-2(trifluoromethyl)phenylacetonitrile; TNFa: tumor necrosis factor $a$; U73122: 1[6-[((17/)-3-methoxyestra-1,3,5[10]-trien-17-yl)amino]hexyl]-1 H-pyrrole-2,5dione; WNT: acronym composed of Wingless/Int-1.

\section{Competing interests}

The authors declare that they have no competing interests.

\section{Authors' contributions}

$\mathrm{CH}, J P D, M B C K, E L, J B O$ and JCV performed experiments and collected data. $\mathrm{CH}, J P D, M B C K, E L, J B O, J C V$ and GS analyzed data and prepared the figures. GS, CH, EA and JPD planned the experiments. CH, GS, JPD, MBCK wrote and $E A, J C V$ revised the manuscript. All authors agreed to the final version of the manuscript.

\section{Acknowledgements}

We thank the Developmental Therapeutics Program at the National Cancer Institute/National Institutes of Health for providing M119 (NSC119910). This work was supported by the Swedish Medical Research Council [K2008-68P20810-01-4, K2008-68X-20805-01-4], Swedish Cancer Society [CAN 2008/539], Karolinska Institutet, the Board of Doctoral Education at Karolinska Institutet (MBCK), the KI-NIH Joint PhD program (JPD), Knut \& Alice Wallenberg Foundation [KAW2008.0149], the Swedish Foundation for International Cooperation in Research and Higher Education STINT, Signhild Engkvists
Foundation, the Foundations of the National Board of Health and Welfare of Sweden. JCV was supported by a FEBS long term fellowship.

\section{Author details}

${ }^{1}$ Dept. Physiology \& Pharmacology, Sec. Receptor Biology \& Signaling, Karolinska Institutet, Nanna Svartz väg 2, Stockholm S-17177, Sweden. ${ }^{2}$ Dept. Medical Biochemistry \& Biophysics, Sec. Molecular Neurobiology, Karolinska Institutet, Retzius väg 8, Stockholm S-17177, Sweden.

Received: 12 December 2011 Accepted: 30 April 2012

Published: 30 May 2012

\section{References}

1. van Amerongen $R$, Nusse R: Towards an integrated view of Wnt signaling in development. Development 2009, 136:3205-3214.

2. Nusse R: Wnts and Hedgehogs: lipid-modified proteins and similarities in signaling mechanisms at the cell surface. Development 2003, 130:5297-5305.

3. Kikuchi A, Yamamoto $H$, Sato A, Matsumoto S: Wnt5a: its signalling, functions and implication in diseases. Acta Physiol (Oxf) 2012, 204:17-33.

4. Freese $J$, Pino D, Pleasure $\mathrm{S}$ : Wnt signaling in development and disease. Neurobiol Dis 2010, 38:148-153.

5. Malaterre J, Ramsay RG, Mantamadiotis T: Wnt-Frizzled signalling and the many paths to neural development and adult brain homeostasis. Front Biosci 2007, 12:492-506.

6. Inestrosa NC, Arenas E: Emerging roles of Wnts in the adult nervous system. Nat Rev Neurosci 2010, 11:77-86.

7. Schulte G: International Union of Basic and Clinical Pharmacology. LXXX. The Class Frizzled Receptors. Pharmacol Rev 2010, 62:632-667.

8. Schulte G, Bryja V, Rawal N, Castelo-Branco G, Sousa KM, Arenas E: Purified Wnt-5a increases differentiation of midbrain dopaminergic cells and dishevelled phosphorylation. J Neurochem 2005, 92:1550-1553.

9. Wong GT, Gavin BJ, McMahon AP: Differential transformation of mammary epithelial cells by Wnt genes. Mol Cell Biol 1994, 14:6278-6286.

10. Shimizu H, Julius MA, Giarré M, Zheng Z, Brown AM, Kitajewski J: Transformation by Wnt family proteins correlates with regulation of beta-catenin. Cell Growth Differ 1997, 8:1349-1358.

11. Semenov MV, Habas R, Macdonald BT, He X: SnapShot: noncanonical Wnt Signaling Pathways. Cell 2007, 131:1378-7.

12. Gao C, Chen YG: Dishevelled: the hub of Wnt signaling. Cell Signal 2009, 22:717-727.

13. Koval A, Purvanov V, Egger-Adam D, Katanaev VL: Yellow submarine of the Wnt/Frizzled signaling: submerging from the $G$ protein harbor to the targets. Biochem Pharmacol 2011, 82:1311-1319.

14. Ahumada A, Slusarski DC, Liu X, Moon RT, Malbon CC, Wang HY: Signaling of rat Frizzled-2 through phosphodiesterase and cyclic GMP. Science 2002, 298:2006-2010.

15. Slusarski DC, Corces VG, Moon RT: Interaction of Wnt and a Frizzled homologue triggers $\mathrm{G}$-protein-linked phosphatidylinositol signalling. Nature 1997, 390:410-413.

16. Schulte G, Bryja V: The Frizzled family of unconventional G-protein-coupled receptors. Trends Pharmacol Sci 2007, 28:518-525.

17. Kilander M, Dijksterhuis J, Ganji RS, Bryja V, Schulte G: WNT-5A stimulates the GDP/GTP exchange at pertussis toxin-sensitive heterotrimeric $G$ proteins. Cell Signal 2011, 23:550-554.

18. Kilander M, Halleskog C, Schulte G: Purified WNTs differentially activate beta-catenin-dependent and -independent pathways in mouse microglia-like cells. Acta Physiol 2011, 203:363-372.

19. Koval A, Katanaev VL: Wnt3a stimulation elicits G-protein-coupled receptor properties of mammalian Frizzled proteins. Biochem J 2011, 433:435-440.

20. Keshet $Y$, Seger $R$ : The MAP kinase signaling cascades: a system of hundreds of components regulates a diverse array of physiological functions. Methods Mol Biol 2010, 661:3-38.

21. Gutkind JS: Regulation of mitogen-activated protein kinase signaling networks by G protein-coupled receptors. SCi STKE 2000, 40:RE1.

22. Dorsam RT, Gutkind JS: G-protein-coupled receptors and cancer. Nat Rev Cancer 2007, 7:79-94.

23. Kettenmann H, Hanisch UK, Noda M, Verkhratsky A: Physiology of microglia. Physiol Rev 2011, 91:461-553.

24. Selcher JC, Atkins CM, Trzaskos JM, Paylor R, Sweatt JD: A necessity for MAP kinase activation in mammalian spatial learning. Learn Mem 1999, 6:478-490. 
25. Saura J: Microglial cells in astroglial cultures: a cautionary note. J Neuroinflammation 2007, 4:26.

26. Kull B, Ferré S, Arslan G, Svenningsson P, Fuxe K, Owman C, Fredholm BB: Reciprocal interactions between adenosine A2A and dopamine D2 receptors in Chinese hamster ovary cells co-transfected with the two receptors. Biochem Pharmacol 1999, 58:1035-1045.

27. Ji RR, Suter MR: p38 MAPK, microglial signaling, and neuropathic pain. Mol Pain 2007, 3:33.

28. Koistinaho M, Koistinaho J: Role of p38 and p44/42 mitogen-activated protein kinases in microglia. Glia 2002, 40:175-183.

29. Kaminska B, Gozdz A, Zawadzka M, Ellert-Miklaszewska A, Lipko M: MAPK signal transduction underlying brain inflammation and gliosis as therapeutic target. Anat Rec (Hoboken) 2009, 292:1902-1913.

30. Halleskog C, Mulder J, Dahlström J, Mackie K, Hortobágyi T, Tanila H, Kumar Puli L, Färber K, Harkany T, Schulte G: WNT signaling in activated microglia is pro-inflammatory. Glia 2011, 1:119-131.

31. Bryja V, Schulte G, Rawal N, Grahn A, Arenas E: Wnt-5a induces Dishevelled phosphorylation and dopaminergic differentiation via a CK1-dependent mechanism. J Cell Sci 2007, 120:586-595.

32. Bryja V, Schambony A, Cajánek L, Dominguez I, Arenas E, Schulte G: Beta-arrestin and casein kinase 1/2 define distinct branches of non-canonical WNT signalling pathways. EMBO Rep 2008, 9:1244-1250.

33. Milligan G: Principles: extending the utility of [35 S]GTP gamma S binding assays. Trends Pharmaco/ Sci 2003, 24:87-90.

34. Dejmek J, Säfholm A, Kamp Nielsen C, Andersson T, Leandersson K: Wnt-5a/ Ca2+-induced NFAT activity is counteracted by Wnt-5a/Yes-Cdc42-casein kinase 1alpha signaling in human mammary epithelial cells. $\mathrm{Mol} \mathrm{Cell} \mathrm{Biol}$ 2006, 16:6024-6036.

35. Kohn AD, Moon RT: Wnt and calcium signaling: beta-cateninindependent pathways. Cell Calcium 2005, 38:439-446.

36. Bernatik O, Ganji RS, Dijksterhuis J, Konik P, Cervenka I, Polonio T, Krejci P, Schulte G, Bryja V: Sequential activation and inactivation of dishevelled in the Wnt/ $\beta$-catenin pathway by casein kinases. J Biol Chem 2011, 286:10396-10410.

37. Marinissen MJ, Gutkind JS: G-protein-coupled receptors and signaling networks: emerging paradigms. Trends Pharmacol Sci 2001, 22:368-376.

38. Lynch MA: The multifaceted profile of activated microglia. Mol Neurobiol 2009, 40:139-156.

39. Sarafi MN, Garcia-Zepeda EA, MacLean JA, Charo IF, Luster AD: Murine monocyte chemoattractant protein (MCP)-5: a novel CC chemokine that is a structural and functional homologue of human MCP-1. J Exp Med 1997, 185:99-109.

40. Opdenakker $G$, Froyen $G$, Fiten $P$, Proost $P$, Van Damme J: Human monocyte chemotactic protein-3 (MCP-3): molecular cloning of the CDNA and comparison with other chemokines. Biochem Biophys Res Commun 1993, 191:535-542.

41. Marzio R, Mauël J, Betz-Corradin S: CD69 and regulation of the immune function. Immunopharmacol Immunotoxicol 1999, 21:565-582.

42. Hanisch UK: Microglia as a source and target of cytokines. Glia 2002, 40:140-155

43. Minghetti $L$, Levi $G$ : Microglia as effector cells in brain damage and repair: focus on prostanoids and nitric oxide. Prog Neurobiol 1998, 54:99-125.

44. Choi MS, Cho KS, Shin SM, Ko HM, Kwon KJ, Shin CY, Ko KH: ATP induced microglial cell migration through non-transcriptional activation of matrix metalloproteinase-9. Arch Pharm Res 2010, 33:257-265.

45. Rosenberg GA, Estrada EY, Dencoff JE: Matrix metalloproteinases and TIMPs are associated with blood-brain barrier opening after reperfusion in rat brain. Stroke 1998, 29:2189-2195.

46. Candelario-Jalil E, Yang $Y$, Rosenberg GA: Diverse roles of matrix metalloproteinases and tissue inhibitors of metalloproteinases in neuroinflammation and cerebral ischemia. Neuroscience 2009, 158:983-994.

47. Ii M, Yamamoto $H$, Adachi $Y$, Maruyama $Y$, Shinomura $Y$ : Role of matrix metalloproteinase-7 (matrilysin) in human cancer invasion, apoptosis, growth, and angiogenesis. Exp Biol Med (Maywood) 2006, 231:20-27.

48. Leeman MF, Curran S, Murray Gl: The structure, regulation, and function of human matrix metalloproteinase-13. Crit Rev Biochem Mol Biol 2002, 37:149-166.

49. Whitelock JM, Murdoch AD, lozzo RV, Underwood PA: The degradation of human endothelial cell-derived perlecan and release of bound basic fibroblast growth factor by stromelysin, collagenase, plasmin, and heparanases. J Biol Chem 1996, 271:10079-10086.
50. Varela-Nallar L, Alfaro IE, Serrano FG, Parodi J, Inestrosa NC: Wingless-type family member $5 \mathrm{~A}$ (Wnt-5a) stimulates synaptic differentiation and function of glutamatergic synapses. Proc Natl Acad Sci U S A 2010, 107:21164-21169.

51. Zhang D, Hu X, Qian L, O'Callaghan JP, Hong JS: Astrogliosis in CNS pathologies: is there a role for microglia?. Mol Neurobiol 2010, 41:232-241.

52. Castelo-Branco G, Sousa KM, Bryja V, Pinto L, Wagner J, Arenas E: Ventral midbrain glia express region-specific transcription factors and regulate dopaminergic neurogenesis through Wnt-5a secretion. Mol Cell Neurosci 2006, 31:251-262.

53. Harterink M, Korswagen HC: Dissecting the Wnt secretion pathway: key questions on the modification and intracellular trafficking of Wnt proteins. Acta Physiol 2012, 204:8-16.

54. Chien AJ, Conrad WH, Moon RT: A Wnt survival guide: from flies to human disease. J Invest Dermatol 2009, 129:1614-1627.

55. De Ferrari GV, Moon RT: The ups and downs of Wnt signaling in prevalent neurological disorders. Oncogene 2006, 25:7545-7553.

56. Yu JM, Jun ES, Jung JS, Suh SY, Han JY, Kim JY, Kim KW, Jung JS: Role of Wnt5a in the proliferation of human glioblastoma cells. Cancer Lett 2007, 257:172-181.

57. Kamino M, Kishida M, Kibe T, Ikoma K, lijima M, Hirano H, Tokudome M, Chen L, Koriyama C, Yamada K, Arita K, Kishida S: Wnt-5a signaling is correlated with infiltrative activity in human glioma by inducing cellular migration and MMP-2. Cancer Sci 2011, 102:540-548.

58. Morioka T, Baba T, Black KL, Streit WJ: Immunophenotypic analysis of infiltrating leukocytes and microglia in an experimental rat glioma. Acta Neuropathol 1992, 83:590-597.

59. Pukrop T, Klemm F, Hagemann T, Gradl D, Schulz M, Siemes S, Trümper L, Binder C: Wnt 5a signaling is critical for macrophage-induced invasion of breast cancer cell lines. Proc Natl Acad Sci U S A 2006, 103:5454-5459.

60. Pukrop T, Dehghani F, Chuang HN, Lohaus R, Bayanga K, Heermann S, Regen T, Rossum DV, Klemm F, Schulz M, Siam L, Hoffmann A, Trümper L, Stadelmann C, Bechmann I, Hanisch UK, Binder C: Microglia promote colonization of brain tissue by breast cancer cells in a Wnt-dependent way. Glia 2010, 58:1477-1489.

61. Klemm F, Bleckmann A, Siam L, Chuang H, Rietkötter E, Behme D, Schulz M, Schaffrinski M, Schindler S, Trümper L, Kramer F, Beissbarth T, Stadelmann C, Binder C, Pukrop T: \{beta\}-Catenin-independent WNT signaling in basal-like breast cancer and brain metastasis. Carcinogenesis 2011, 32:434-442.

62. Kawano Y, Kypta R: Secreted antagonists of the Wnt signalling pathway. J Cell Sci 2003, 116:2627-2634.

63. Kilander M, Halleskog C, Schulte G: Purified WNTs differentially activate beta-catenin-dependent and -independent pathways in mouse microglia-like cells. Acta Physiol 2011, 203:363-72.

doi:10.1186/1742-2094-9-111

Cite this article as: Halleskog et al: Heterotrimeric $\mathrm{G}$ protein-dependent WNT-5A signaling to ERK $1 / 2$ mediates distinct aspects of microglia proinflammatory transformation. Journal of Neuroinflammation 2012 9:111.

\section{Submit your next manuscript to BioMed Central and take full advantage of:}

- Convenient online submission

- Thorough peer review

- No space constraints or color figure charges

- Immediate publication on acceptance

- Inclusion in PubMed, CAS, Scopus and Google Scholar

- Research which is freely available for redistribution 